\title{
EL TESTIMONIO COMO IMPOSIBILIDAD DE SOBREVIVIR A LA CONSCIENCIA DE LA MUERTE
}

\author{
Daniel Arroyo Rodríguez \\ University of Michigan \\ Comment raconter une vérité peu crédible, \\ comment susciter l'imagination de l'inimaginable?
}

(Jorge Semprún)

Uno de los testimonios más destacados sobre la supervivencia al horror de un campo de concentración nazi por parte de un prisionero español es sin duda la obra autobiográfica de Jorge Semprún La escritura o la vida. Este testimonio no constituye simplemente un relato sobre su supervivencia física, sino que da también cuenta de la imposibilidad de superar la consciencia de la muerte en los años posteriores a esta experiencia. Siguiendo la filosofía de Martin Heidegger expuesta en Ser y Tiempo, este testimonio responde a la intención del autor de salvar el carácter ontológico de su consciencia como ser-para-la-muerte y de insertarse en una existencia inauténtica como ser-en-el-mundo. De esta forma, Semprún trata de superar la culpabilidad como fenómeno existencial y el aislamiento que implica la consciencia de su finitud, los cuales se derivan de la experiencia colectiva de la muerte en un campo de concentración. Para ello, el superviviente aborda el testimonio como un acto a través del cual expresar su consciencia de la muerte a través de paradigmas inauténticos, rearticulando su consciencia ontológica en base a la temporalidad infinita, la habladuría y la curiosidad. En base a estos paradigmas ónticos, Semprún revierte el proceso de constitución de la consciencia ontológica que expone Heidegger. En lugar de indagar sobre el significado de la existencia auténtica, el autor persigue la articulación óntica de su consciencia como ser-para-la-muerte, de forma que pueda dar cuenta de su propia historicidad, lo cual, según el testigo, y en desacuerdo con Heidegger, sólo es posible desde la existencia como ser-en-el-mundo. Si bien Semprún no logra superar su consciencia auténtica, propósito inicial de su relato, el acto de testimoniar le permite romper con el estado no relacional de esta forma de existencia, lo cual posibilita su existencia como ser-para-la-muerte-con-cl-otro. Este aspecto distingue el testimonio del escritor español del de otros supervivientes, como Paul Celan y Primo Levi, quienes tratan de comunicar su consciencia ontológica a un receptor inmerso en una existencia inauténtica, sin lograr reestablecer su existencia como ser-con-el-otro: 


\section{EL TESTIMONIO COMO IMPOSIBILIDAD DE SOBREVIVIR...}

En primer lugar conviene destacar el carácter autobiográfico del relato, siendo el escritor simultáneamente sujeto y objeto de su narración. No obstante, dada la imposibilidad de experimentar de forma individual la experiencia que aborda -la muerte-el autor no puede ofrecer un testimonio integral, pues, lógicamente, no ha experimentado este acontecimiento en primera persona. En este sentido, el superviviente no constituye un superstes, es decir, un testigo que ha vivido una experiencia de principio a fin (Agamben 17), o lo que Primo Levi denomina como i sommersi, refiriéndose a través de este término a aquellos que perecieron en los campos de concentración. Semprún trata de superar los límites inherentes al testimonio de supervivencia relatando la experiencia de la muerte como una vivencia propia pero que de forma ambivalente es experimentada de forma colectiva ${ }^{\prime}$. De esta forma, el escritor trata de solventar la imposibilidad de revelar la experiencia integral del óbito propio, y de superar la incredulidad inherente a la recepción de este tipo de relatos²:

Pero no había, jamás habría supervivientes de las cámaras de gas Nazis. Nadie jamás podrá decir: yo estuve allí. Se podía estar alrededor, o antes, o al lado, como los individuos del Sonderkommando. De ahí la angustia de no resultar creíble, porque no se está muerto, precisamente porque se ha sobrevivido (64).

El superviviente español concibe la experiencia colectiva de la muerte como un proceso fraternal que relaciona al Dasein con el Dasein del otro, constituyendo esta consciencia de la finitud una forma de existencia común dentro del campo ${ }^{3}$. Así, la muerte ajena se convierte en parte de la experiencia propia, al ser una vivencia compartible como parte de un ser-para-la-muerte-con-el-otro (mit-Seinzum-Tode). El testigo se convierte por tanto en el medio del testimonio a través del cual se relata esta experiencia terminal como evento que sobrepasa la significación de lo individual (Felman 24): «Y no obstante, habremos vivido la experiencia de la muerte como una experiencia colectiva, fraternal, además fundiendo nuestro estar-juntos... como un mit-Sein-7um-Tode» (105).

Desde una perspectiva freudiana, esta experiencia transferida de la finitud es el resultado del carácter masivo con el que este acontecimiento tiene lugar en los campos de concentración. Al igual que en la guerra, la omnipresencia de la muerte no permite la percepción de este fenómeno como una casualidad, es decir, de forma inauténtica. La exposición continua y la convivencia con la muerte en el día a día hace de este acontecimiento una experiencia colectiva, siendo la única diferencia entre los distintos Daseins la distancia temporal que los separa de la certidumbre de este final ${ }^{4}$ :

Compartíamos eso, esa certeza, como un mendrugo de pan. Compartíamos esa muerte que crecía, ensombreciendo su Mirada, como un mendrugo de pan: signo de fraternidad... [La muerte] nos concernía

1.- Si aceptamos esta posibilidad de experimentar la muerte como experiencia colectiva, el testimonio de Semprún puede considerarse como un relato autotanatográfico en lugar de autobiográfico, como indica Ursula Tidd en su artículo "The Infinity of 'Testimony and Dying in Jorge Semprún's Holocaust Authotanatographies".

2.- Según Jacques Derrida, el testimonio constituye un acto de fe performativo en el que el testigo se compromete a decir la verdad, requiriendo en base a este compromiso el ser creído por el receptor: «I affirm (rightly or wrongly, but in all good faith, sincerely) that that was or is present to me, in space and time (thus, perceptible), and although you do not have access to it, no the same access, you, my addressees, you have to believe me, because I am committed to telling you the truth. Believe me. You have to believe me» (Self-Unsealing 189).

3.- Por Dasein nos referimos, en términos generales y siguiendo la teoría hedeiggeriana, al ser que inquiere sobre sus posibilidades de existencia: "This entity which each of us is himself and which includes inquiring as one of the possibilities of its Beings, we whall denote by the term "Dasein"» (Heidegger 27). No obstante, conviene destacar un doble uso de este término en la lengua alemana. Por un lado, como término filosófico, se refiere prácticamente a cualquier tipo de existencia (la "existencia" de D-s, por ejemplo). Como término ordinario, en alemán, se utiliza también como sinónimo de persona. En el presente ensayo utilizaremos este término según esta interpretación, evitando traducir esta palabra para no violar así el doble significado de este término en su lengua original.

4.- «Los hombres mueren de verdad, y no ya aisladamente, sino muchos, decenas de millares, y a veces en un día. Y no es ya tampoco una casualidad... La acumulación pone un término a la impresión de casualidad» (Freud 2111). 


\section{DANIEL ARROYO RODRÍGUEZ}

a todos, era la sustancia de nuestras relaciones. No éramos otra cosa más que eso, nada más -nada menos, tampoco-que esa muerte que crecía. La única diferencia entre nosotros era el tiempo que nos separaba de ella, la distancia todavía por recorrer (30).

Más aún, dada la regulación formal a la que está sujeta, la muerte dentro del campo de concentración constituye una experiencia del Mal radical, aspecto que la distingue de la muerte experimentada en la vida ordinaria como fenómeno natural. El superviviente alude a este concepto filosófico durante una conversación con un oficial americano, distinguiéndolo de la mera experiencia del Mal que tiene lugar en la experiencia diaria:

Lo esencial -digo al teniente Rosenfeld- es la experiencia del Mal. Ciertamente, esta experiencia puede tenerse en todas partes... No hacen ninguna falta los campos de concentración para conocer el Mal. Pero aquí, esta experiencia habrá sido crucial, y masiva, lo habría invadido todo, lo habrá devorado todo... Fs la experiencia del Mal radical... (103).

Esta alusión al Mal radical constituye una referencia a Inmanuel Kant, quien define este concepto - das radikal Böse-como la subordinación de la ley a la satisfacción sensible, lo cual permite probar las inclinaciones humanas. Los campos de exterminio no constituyen solamente una experiencia masiva de la mucrte, sino una experiencia de este fenómeno, es decir, del potencial de destrucción de la vida ajena a través de la subordinación consciente e intencionada de la ley a una maldad inexplicable que constituye su razón de ser. De hecho, en esta experiencia del Mal radical, la ley no persigue la regulación de la vida, es decir, una biopolítica, sino la regulación de la muerte, constituyendo de este modo lo que Agamben denomina como tanatopolítica (Agamben 87).

Aparte de superar las limitaciones propias del testigo no integral, la percepción colectiva de la muerte permite al autor pseudo-testimoniar por otros prisioneros que no logran sobrevivir, como es el caso de Maurice Halbwachs. Semprún apropia -o hereda, siguiendo una terminología derridianala muerte del sociólogo francés, narrándola como si de su experiencia propia se tratase: "Halbwachs estaba muerto. Yo había vivido la muerte de Halbwachs" (57). Más aún, el superviviente adopta la noción de paradigmas colectivos a través de los cuales el difunto profesor formula su teoría sobre la memoria colectiva, lo que permite a Semprún concebir la mucrte dentro de un marco de percepción común en base a la experiencia compartida en el campo de concentración ${ }^{5}$. Por ello, podemos afirmar que Halbwachs testimonia por mediación del relato de Semprún, exponiendo no sólo su experiencia de la muerte, sino haciendo uso también de los preceptos teóricos formulados por el finado, y por tanto, de la perspectiva del mismo.

Esta noción de muerte colectiva se opone a la interpretación de Heidegger de este fenómeno como una experiencia no relacional (Unbezïgliche). De acuerdo con este filósofo, la muerte se revela como esa posibilidad que es más propia e íntima del individuo y que no puede ser apropiada por otro (Heidegger 294). Esta perspectiva es también común al pensamiento de Epicuro y al del filósofo alemán Ludwig Wittgenstein, quienes niegan la posibilidad de experimentar la muerte propia. Semprún, siguiendo la teoría sociológica de Halbwachs, afirma esta posibilidad, sosteniendo que es posible a través de la experiencia compartida con otros individuos:

Entonces fue cuando me acordé de Ludwig Wittgenstein. 'La muerte no es un acontecimiento de la vida. La muerte no puede ser vivida', había escrito ese cabronazo de Wittgenstein. Yo había vivido la muerte de Morales, no obstante, la estaba viviendo. Como un año antes había vivido la muerte de Halbwachs. ¿Y acaso no había vivido asimismo la muerte del joven soldado alemán que cantaba la paloma? ¿La muerte que yo le había dado? ¿No había vivido acaso el horror, la compasión de todas estas muertes? ¿De toda la muerte? (209).

5.- Halbwachs expone esta teoría en su obra La memoria colectiva. 


\title{
EL TESTIMONIO COMO IMPOSIBILIDAD DE SOBREVIVIR...
}

La experiencia colectiva de la muerte sitúa al sujeto en un espacio intermedio, al encontrarse entre los vivos pero siendo consciente de la finitud de su existencia, constituyendo de esta forma un muerto en vida, un espectro. De hecho, cuando el testigo abandona Buchenwald se enfrenta al mundo de la existencia inauténtica, causando el espanto de los brigadas con los que se encuentra en su camino, lo que le lleva a cuestionar si realmente ha sobrevivido:

\begin{abstract}
Me he visto en su mirada horrorizada por primera vez desde hace dos años. Me han estropeado esta primera mañana, los tres tipos estos. Estaba convencido de haberlo superado con vida. De vuelta a la vida, cuando menos. No es tan evidente. Tratando de adivinar mi mirada en el espejo de la suya, no parece que me encuentre más allá de tanta muerte (26).
\end{abstract}

La visión a la que se enfrentan los brigadas es la de un espectro, es decir, una corporalidad que se encuentra entre la vida y la muerte. Es una presencia física y visual que se halla rodeada de un aura de fenomenalidad, como si de un espíritu se tratase, pues es una aparición de lo desaparecido, de un Dasein que ya no existe en cl espacio y en el tiempo pero que está ahí. Es decir, como (re)aparecido, el superviviente es un ser presente que refleja a su vez una ausencia, encontrándose entre la existencia y su negación:

El espectro se convierte más bien en cierta "cosa" difícil de nombrar: ni alma ni cuerpo, y una y otro. Pues son la carne y la fenomenalidad las que dan al espíritu su aparición espectral, aunque desaparezca inmediatamente en la aparición, en la venida misma del (re)aparecido o en el retorno del espectro. Hay algo de desaparecido en la aparición misma como reaparición de lo desaparecido (Espectros 20).

El carácter espectral del (re)aparecido indica también la existencia de una disyunción temporal, en la que la existencia del ser en el espacio y en el tiempo implica, no solamente una existencia en el presente, sino también en un pasado que no es superado y en un futuro sobre el que se proyecta ${ }^{6}$. Por consiguiente, el espectro es un elemento que existe en el espacio y en cl tiempo, temporalidad que, no obstante, se encuentra dislocada: «El espectro es algo que sólo puede ser pensado en un tiempo de presente dislocado, en la juntura de un tiempo radicalmente disyunto, sin conjunción asegurada» (Espectros 31).

La visión del espectro es además acompañada de un olor a carne quemada procedente del crematorio y de un silencio absoluto, lo que produce en los brigadas náusea y horror, pues esta aparición les hace fugazmente testigos de la posibilidad de la muerte y de la no-existencia reflejada por el superviviente:

\footnotetext{
“QQué pasa? -digo, irritado, sin duda cortante. ¿Es el silencio del bosque lo que tanto os extraña? Gira la cabeza hacia los árboles alrededor. Los otros también. Aguzan el oído. No, es el silencio. Nada les había llamado la atención, no había oído el silencio. Quien les llena de espanto soy yo, eso es todo, manifiestamente $[\ldots] ; E l$ olor de carne quemada, eso es! Se sobresaltan, se miran unos a otros. Con un malestar casi palpable. Una especie de hipido, de náusea" (17).
}

Ante esta aparición, los brigadas adquieren consciencia de la necesidad de contar con aquello que vuelve en forma de espectro, lo cual implica a su vez una nueva forma de existencia por parte de aquellos que no han experimentado la muerte de forma colectiva. Más aún, esta nueva forma de existencia, y la responsabilidad que de ella se deriva, suponen también la imposibilidad de un olvido activo, de dejar a los espectros, a los muertos, en un pasado en el que nunca fueron enterrados y en el que no recibieron ningún duelo, lo cual reclama una política de la memoria, de la herencia y de las generaciones (Espectros 12).

6.- «En el fondo, el espectro es el porvenir, está siempre por venir, sólo se presenta como lo que podría venir o desaparecer” (Espectros 52). 


\section{DANIEL ARROYO RODRÍGUEZ}

El carácter espectral del (re)aparecido revela también la distancia entre el superviviente y el sujeto óntico colectivo, pues éstos están sujetos a distintas formas de existencia?. Esta separación implica tambićn la imposibilidad de la comunicación entre estos individuos, al no existir un referente compartido entre ambos. El carácter ontológico de la conciencia del autor sitúa su perspectiva en el ámbito de lo auténtico, perspectiva que se caracteriza principalmente por la consciencia de la finitud de la existencia como hecho innegable de la experiencia (Heidegger 301). Por otra parte, cl sujeto óntico colectivo se encuentra en una realidad inauténtica, caracterizada por la continua negación de la finitud de la existencia ${ }^{8}$. Por ello, el lenguaje ordinario, de carácter inauténtico, se muestra insuficiente para desvelar la consciencia del testigo, al tener como referente realidades ónticas, no ontológicas. El humo y la chimenea son, por ejemplo, dos términos cuyos referentes no permiten revelar la esencia que estos significantes tienen para el superviviente. Como consecuencia, la única forma posible de aproximarse a la esencia ontológica de estos términos es a través de la mera conjetura y de la interpretación superficial que se produce desde la existencia inauténtica:

Pero no pueden comprender de verdad. Habrán captado el sentido de las palabras probablemente. Humo: todo el mundo sabe lo que es, cree saberlo. En todas las memorias de los hombres hay chimeneas que humean. Rurales ocasionalmente, domésticas: humos de dioses lares. Pero de este humo de aquí, no obstante, nada saben. Y nunca sabrán nada de verdad. Ni supieron éstos, aquel día. Ni todos los demás desde entonces (22-23).

La esencia ontológica que evocan el humo y las cenizas para el superviviente del campo de concentración es significativa solamente para aquellos Daseins que comparten la consciencia de la finitud, siendo éstos los únicos que, al menos de forma potencial, pueden desvelar su esencia auténtica. Para estos individuos la consciencia ontológica compartida radica en la negación común de la existencia como ser-en-el-mundo; convertido en humo y cenizas, el Dasein del otro deja de existir en el espacio y en el tiempo, lo que implica también la negación de la existencia del superviviente como ser-con-el-otro ${ }^{9}$ : $« B y$ reason of this with-like (Mithaften) ${ }^{10}$, Being-in-theworld, the world is always the one that I share with Others. The world of Dasein is a with-world (Mitwelt). Being-in is Being-with-Others»" (Heidegger 155).

Si la consciencia ontológica no puede ser comunicada al sujeto óntico colectivo de forma directa, la intención del testigo de articular esta conciencia le permite mantener abierta la posibilidad de una comunicación con otros Daseins cuya existencia radica también en la consciencia auténtica del ser-para-la-muerte. Este tipo de comunicación constituye un intento por sobrevivir mediante el establecimiento de una relación del Dasein con el otro y de superar el aislamiento que caracteriza

7.- Por sujeto óntico colectivo nos referimos al Dasein en su existencia inauténtica, la cual comparte con otros Daseins. Heidegger utiliza el término "das Mann" para referirse al Dasein en su carácter colectivo y ajeno a la consciencia de la finitud, estando inmerso en la apariencia de la existencia inauténtica. El término utilizado en la traducción de la obra de Heidegger al inglés para referirse a este concepto es theyself. Dada la ambiguedad del término y la dificultad que presenta su traducción, optamos por emplear una descripción aproximada de este concepto. Por óntico, como término utilizado de forma independiente, nos referimos, siguiendo la etimología del término, al ser, a lo que es, sin llegar a trascender a lo ontológico. Del griego ốv, ôvtos.

8.- La percepción inauténtica de la muerte en la teoría hedeiggeriana concuerda con la actitud ante la muerte descrita por Freud en "El porqué de la gucra": «Mostramos una patente inclinación a prescindir de la muerte, a eliminarla de la vida... La muerte propia es, desde luego, inimaginable, y cuantas veces lo intentamos podemos observar que continuamos siendo en ello meros espectadores" (Freud 2110).

9.- «In Being and Time being-with is one of the equiprimordial existentials of being-there. As formal indication it refers to the reciprocity of mutual comporting. Others are always there with me and I am always there with others" (Denker 64).

10.- Otros términos utilizados en alemán para este concepto son Mitsein y Mit-dasein.

11.- $« \ln$ Being and Time he describes being-there (Dasein) as being-with (Mitwelt). The world is always already the world that I share with others» (Denker 241). 


\section{EL TESTIMONIO COMO IMPOSIBILIDAD DE SOBREVIVIR...}

a la existencia ontológica del ser-para-la-muerte. De acuerdo con esta interpretación, podemos afirmar que tanto Celan como Primo Levi buscan un receptor potencial que pueda desvelar la esencia auténtica de su relato. De hecho, Semprún, como receptor, se identifica con estos poetas, los cuales han experimentado la finitud de la existencia y han tratado de transmitir su consciencia ontológica a través del testimonio lírico:

Siempre he tenido suerte con los poetas. Quicro decir: mis encuentros con sus obras siempre han sido oportunos. Siempre me he topado, en el momento oportuno, con la obra poética que podía ayudarme a vivir, a hacerme progresar en la agudeza de mi conciencia del mundo. Así me sucedió con César Vallejo y también más adelante con René Char y con Paul Celan (183).

Semprún compara su relación con la escritura con la experiencia de Primo Levi y de Celan, reflexionando sobre la relación existente entre el acto de testimoniar y la supervivencia del testigo. Por un lado el testimonio supone una liberación del estado no relacional al que se ve sometido el ser-para-la-muerte en su modalidad auténtica de existencia a través de la comunicación de esta consciencia y del establecimiento de una forma de existencia como ser-con-el-otro. Esta comunicación, no obstante, en ningún momento implica la superación del carácter ontológico del ser-para-la-muerte, pues no revierte en el establecimiento de una relación inauténtica con el Dasein del otro o con el sujeto óntico colectivo. Más aún, la intención de comunicar la consciencia ontológica supone al mismo tiempo una nueva inmersión en la temporalidad de la existencia, lo que lleva de nuevo al testigo, según expresa Semprún, a debatirse entre la vida y la muerte:

Así como la escritura liberaba a Primo Levi del pasado, apaciguaba su memoria... a mí me hundía otra vez. en la muerte, me sumergía en ella. Me ahogaba en el aire irrespirable de mis borradores, cada línea escrita me sumergía la cabeza debajo del agua, como si estuviera de nuevo en la bañera de la villa de la Gestapo, en Auxerre. Me debatía para sobrevivir. Fracasé en mi intento de expresar la muerte para reducirla al silencio: si hubiera proseguido, la muerte, probablemente, me habría hecho enmudecer (268).

El enmudecimiento al que alude Semprún se refiere con toda probabilidad al suicidio, desenlace común a Primo Levi y Celan, quienes no consiguen superar la consciencia de su finitud. Teniendo en consideración estas experiencias ajenas, el escritor español, en un primer momento, opta por el olvido activo y por el silencio como única posibilidad de supervivencia: «La vida todavía era vivible. Bastaba con olvidar, con decidirlo firme, brutalmente. La elección cra simple: la escritura o la vida» (226). Semprún respalda su perspectiva apropiándose de la conclusión a la que llega el italiano -o heredándola- tras años de escritura y aplicándola a su experiencia personal ${ }^{12}$ : «Nulla era vero all'infuori del Lager. Il resto era breve vacanza o inganno dei sensi, sogno...» (269). No obstante, cuatro décadas después, $\mathrm{el}$ autor rompe con su silencio, optando por un testimonio cuyo objetivo no es el de verbalizar el carácter auténtico de su existencia, sino el de cubrir con el velo de lo inauténtico la certeza de la finitud propia. Para ello, el superviviente español trata de articular la conciencia auténtica del ser-para-la-muerte como si fuese una realidad óntica, redefiniendo de este modo su cxistencia como ser-en-el-mundo:

Y sin duda yo mismo sabía desde el fondo más arcaico de un conocimiento visceral, que iba a revivir, a retomar el curso de una vida posible. Incluso lo estaba deseando, ansiando violentamente el porvenir: las músicas, los soles, los libros, las noches en vela, las mujeres, la soledad. Sabía que era necesario y justo revivir, volver a la vida ... (136-137).

Esta traslación de lo auténtico a lo inauténtico implica una interpretación del testimonio, no como producto exclusivamente discursivo, sino como acto que forma parte del proceso

12.- En relación al suicidio de Primo Levi como resultado del fracaso de expresar su consciencia ontológica, comenta un periodista anónimo del New Yorker: «The efficacy of all his words had somehow been canceled by his death - that his hope, or faith, was no longer usable by the rest of us» (New Yorker, 11 de mayo de 1987. Citado por Homer. P. 156). 


\section{DANIEL ARROYO RODRÍGUEZ}

de supervivencia, siendo su objetivo la superación del estado no relacional de la consciencia auténtica. No obstante, y de forma ambivalente, si bien Semprún concibe la muerte como un proceso que puede ser experimentado de manera colectiva, en el caso de la muerte propia esta experiencia adquiere un sentido íntimo e intransferible, ateniéndose al carácter no relacional de la muerte que expone Heidegger: «Nadic puede ponerse en tu lugar, pensaba yo, ni siquiera imaginar tu lugar, tu arraigo en la nada, tu mortaja en el cielo, tu singularidad mortífera» (248). Por tanto, el autor percibe la muerte desde una doble perspectiva: como experiencia colectiva de un acontecimiento y, por otro lado, como vivencia no relacional, siendo la primera un proceso preliminar a la experiencia de la muerte individual como fenómeno no compartible ${ }^{13}$ :

Nada me distraería de mi dolor. Nada sino la muerte, por descontado. No el recuerdo de la muerte, de la vivencia que tenía de ella: la experiencia de salir a su encuentro con los otros, los míos, de compartirla con ellos, fraternalmente. De ser para la muerte con los otros: los compañeros, los desconocidos, mis semejantes, mis hermanos: el otro, el prójimo. De fundamentar en ella nuestra libertad común. Así pues, no es este recuerdo de la muerte, sino la muerte personal, el óbito ... (172).

En este enfrentamiento al óbito personal, el Dasein, en su modalidad de existencia auténtica, percibe su muerte como una experiencia sujeta a una temporalidad delimitada. En contraposición a esta temporalidad, el tiempo óntico constituye un concepto infinito desde el que no es posible concebir la finitud propia. De hecho, esta incertidumbre permite al sujeto óntico evadir la consciencia de la muerte, diluyendo esta noción a través del carácter indeterminado del tiempo, mientras que el sujeto ontológico, por el contrario, es consciente de la finitud de su existencia, lo que le lleva a cuestionar su significación (Seinsfrage) ${ }^{14}$.

A diferencia de la perspectiva inauténtica, la conciencia de la posibilidad de la muerte sobrepasa la mera certeza del acontecimiento futuro, yendo más allá de la crónica de eventos y centrándose en la muerte como posibilidad significativa. Esta posibilidad no es meramente una función lógica que se cumplirá en un futuro indeterminado; por el contrario, constituye una forma esencial de existencia, en la que el Dasein experimenta la libertad de poder captar plenamente la capacidad del ser o su negación ${ }^{15}$. Ello permite a Semprún cuestionar la posibilidad de revelación de su consciencia auténtica a través de una escritura no poética o, por el contrario, la posibilidad del silencio como permanencia en la existencia del ser-para-la-muerte, optando por la primera opción en un intento por sumergirse en la existencia inauténtica ${ }^{16}$.

Si el desarrollo de la conciencia ontológica implica el aislamiento con respecto al colectivo óntico, la supervivencia, de forma inversa, requiere la ruptura del silencio que inicialmente adopta el escritor español, de forma que sca posible la aproximación a la existencia inauténtica del seren-el-mundo. El acto de sobrevivir no concluye por tanto con la supervivencia física, sino que se convierte en un proceso de alejamiento de la consciencia de la finitud y del aislamiento que acompaña al superviviente como parte de su existencia:

Dos años de eternidad glacial, de intolerable muerte me separaban de mí mismo. ¿Volvería a mí, algún día? ¿A la inocencia, cualquiera que fuera el afán de vivir, de la presencia transparente a uno mismo? ¿Sería para

13.- «It shows us that my death is my own. I alone will die my death... if there is anything that is my own, it is my death. Because it is my own, it cannot be shared by anyone» (Gelven 150).

14.- «Death, of course, does reveal the terrible temporality of our existence. Because death focuses upon our own existence rather than upon the inauthentic they-self (for the they-self does not die), it becomes the ground for authentic existente» (Gelven 141).

15.- «In Being and Time freedom is being-there's most unique possibility to be itself or not itself» (Denker 96).

16.- " $[. .$.$] being-towards-death has an authentic and an inauthentic mode. Inauthentic being-towards-death flees in fear$ from death as its most unique possibility: the possible impossibility of being there's existence. In fear being-there tries to remain indifferent to its uttermost possibility and consider death as something that does not concern it just yet. In authentic being-towards-death, being-there does not evade death as its most unique possibility" (Denker 64). 


\section{EL TESTIMONIO COMO IMPOSIBILIDAD DE SOBREVIVIR...}

siempre jamás ese otro ser que había atravesado la muerte, que se había alimentado de ella, que se había deshecho en ella, evaporado, perdido? (121).

Una forma a través de la cual el testigo trata de adquirir una consciencia inauténtica es a través de la superación del fenómeno existencial de la culpabilidad (Schuld). Este fenómeno, al igual que la muerte, retrae al Dasein sobre sí mismo, siendo por ello fundamental en la constitución de la consciencia ontológica. La superación de este fenómeno implica su negación, pues la culpabilidad constituye una forma de existencia negativa, de nulidad (Nichtigkeit). Esta culpabilidad no es específica, sino general y condicional, lo que implica la incertidumbre sobre el origen de este fenómeno. En su negación de la culpa, Semprún concibe este fenómeno, no como algo general y condicional, sino como algo derivado, es decir, desde una percepción inauténtica: «El caso es que no era un sentimiento de culpabilidad lo que me embargaba. Ese sentimiento no es más que algo derivado, vicario. La angustia desnuda de vivir le es anterior: la angustia de haber nacido» (155). El autor distingue por tanto entre la culpabilidad como fenómeno ontológico, el cual identifica con el sentimiento de angustia, y la culpabilidad óntica y derivada, cuya experiencia niega ${ }^{17}$. Esta distinción permite al autor adaptar su testimonio a la perspectiva de un lector no familiarizado con la filosofía hedeiggeriana, presumiblemente mayoritario, evitando una posible confusión entre ambas formas de percibir la noción de culpabilidad.

La negación de la culpabilidad óntica, es decir, como sentimiento de responsabilidad jurídica y psicológica por un daño inflingido de forma directa o indirecta sobre otro u otros individuos, guarda también relación con el carácter político del testimonio de Semprún ${ }^{18}$. El autor trata de evitar la interpretación del concepto de culpa como sentimiento derivado de una posible responsabilidad asociada con su colaboración forzada con la estructura burocrática de Buchenwald. En concreto, Semprún ejerce como administrativo en el centro de estadísticas del campo, ocupación que le sitúa en una posición ambigua entre los prisioneros comunes y los guardianes, siendo consciente de la posición intermediaria y ambivalente en la que se encuentra:

Entonces, a gritos, le traté de Arschloch, de tonto del culo, y le ordené que me trajera a su jefe de bloque. Trabajo en la Arbeitstatistik le dije. ¿Quería acabar figurando en una lista de transporte? Me veía a mí mismo hablándole así, me oía decirle todo aquello a gritos y me encontraba bastante ridículo. Incluso bastante infame, por amenazar con mandarlo a un transporte. Pero ésas eran las reglas del juego y no era yo quien había instaurado esas reglas en Buchenwald. En cualquier caso, la alusión a la Arbeitstatistik obró el milagro. Era la oficina del campo donde se distribuía la mano de obra en los diferentes kommandos de trabajo. También donde se organizaban los transportes con destino a los campos exteriores, generalmente más duros que el propio campo de Buchenwald. Nicolai adivinó que no me estaba echando un farol, que de verdad estaba trabajando en las oficinas. Su actitud se suavizó en el acto (34).

Su función en el campo forma parte, no obstante, de la propia tortura a la que está sujeto el autor como prisionero, pues su supervivencia depende de su colaboración administrativa con sus ejecutores. Esta función consiste principalmente en la organización de los grupos de trabajo y en la eliminación del nombre de los fallecidos de las fichas administrativas, complctando de esta forma la eliminación nominal de aquellos prisioneros que previamente ya habían sido eliminados físicamente:

Saqué la ficha de Maurice Halbwachs, borré su nombre: un vivo podría ahora ocupar el lugar de ese muerto... Hice todos los gestos necesarios, borré cuidadosamente su apellido, Halbwachs, su nombre de pila, Maurice: todas sus señas de identidad. Tenía su ficha rectangular a la palma de la mano, volvía a estar blanca y virgen: otra vida podría inscribirse en ella, una muerte nueva (56).

17.- La perspectiva inauténtica que adopta Semprún sobre la culpabilidad puede deberse, siguiendo una interpretación alternativa, a la confusión del mismo autor entre el carácter ontológico de la culpabilidad y la interpretación óntica de este concepto. No obstante, dado el conocimiento que muestra el autor de la obra de Heidegger, resulta poco probable que sea éste el caso, por lo que interpretamos que existe una intencionalidad por parte del autor.

18.- Jorge Semprún fue ministro de cultura en España entre los años 1988 y 1991. 


\section{DANIEL ARROYO RODRÍGUEZ}

La obliteración del nombre implica la consiguiente eliminación de la identidad del cadáver, la cual priva al finado del derecho a la muerte escrita, pues, como indica Gusmán, el nombre excede la existencia vital de un sujeto y hace de un esqueleto un cadáver que necesita de una tumba (17). Tanto la incineración como la eliminación del nombre impiden que el fallecido constituya un cadáver, privándole de la individualidad y del sentido de su propio óbito e insertándolo en la experiencia de la muerte como evento que afecta de forma indiscriminada a una masa indistinta de objetos no humanos (Felman 31). Más aún, esta eliminación no permite llevar a cabo el trabajo del duelo pues, como indica Derrida, este proceso requiere saber quién está muerto y dónde está enterrado, pues la confusión y la duda que se derivan de la eliminación física y nominal masiva de los prisioneros impiden la superación de la pérdida. Los incinerados y aquellos cuyos nombres desaparecen son por tanto muertos anónimos de cuya existencia no queda constancia y que no han recibido ningún duelo, lo que previene el olvido de los mismos como parte de una responsabilidad heredada por los supervivientes. De este modo, los incinerados no son muertos, cadáveres, sino espectros indóciles que resisten a su propia desaparición a pesar de la necesidad-imposible en cualquier caso- de un olvido activo, es decir, de «dejar a los muertos enterrar a los muertos» (Espectros 196).

La sistematicidad con la que el administrativo elimina el nombre del fallecido evoca el procedimiento a través del cual el Sonderkommando aniquila y disuelve físicamente a los prisioneros en los hornos crematorios, incluso cuando el carácter archivístico de su función le mantenga a una distancia física con respecto a los cadáveres, lo cual le convierte en un testigo excepcional del carácter cuantitativo de esta eliminación. Por consiguiente, y según podemos observar en el relato de Semprún, el Sonderkommando no actúa de forma aislada, sino que forma parte de todo un mecanismo de eliminación física y nominal llevada a cabo, en muchos casos, con la colaboración forzada de los mismos prisioneros ${ }^{19}$ :

The SS implicated concentration camp inmates - criminals, politicals, jews - in their crimes by making them responsible for a large part of the administration, thus confronting them with the hopeless dilemma whether to send their friends to their death, or to help murder other men who happened to be strangers and forcing them in any event, to behave like murderers (Arendt 452).

Semprún se encuentra en un espacio ambiguo, al ser colaborador administrativo de los cjecutores y del sistema que le relega a la condición de prisionero. Este espacio indefinido entre prisionero y ejecutor-ya sea un ejecutor físico o administrativo- se asemeja a lo que Primo Levi denomina la zona gris y que Agamben define como la indeterminación entre víctima y opresor: "It is the zone in which the "long chain of conjuction between victim and executioner" comes loose, where the oppressed becomes oppressor and the executioner in turn appears as victim" (Agamben 21). En cualquier caso, y como prisionero, el testigo no es indiferente a la muerte de sus compañeros, viéndose sometido a un doble sentimiento de tristeza y de identificación con la muerte ajena, sentimientos que - desde una lectura psicoanalítica- constituyen la otra cara del sentimiento de culpabilidad ante la muerte del otro. De acuerdo con esta perspectiva, la culpabilidad se deriva de una dualidad entre el amor y el impulso asesino original que Freud atribuye a lo que él denomina el hombre primordial, el cual sigue dominando en las relaciones humanas:

Hizo entonces, en su dolor, la experiencia de que también él mismo podía morir, y todo su ser se rebeló contra ello. Cada uno de aquellos seres amados era, en efecto, un trozo de su propio y amado yo. Mas, por otro lado, tal muerte le era, sin embargo, grata, pues cada una de las personas amadas integraban también algo ajeno y extrano a él (Freud 2112-2113).

19.- Esta situación, en la que los prisioneros colaboran en la eliminación de sus semejantes, es descrita por Homer como "infierno hobbesiano", definiéndolo como una guerra de todos contra todos en la que el único objetivo es la supervivencia propia (Homer 23-45). 


\section{EL TESTIMONIO COMO IMPOSIBILIDAD DE SOBREVIVIR...}

En relación a la superación de la culpabilidad podemos concluir que Semprún no supera este fenómeno ontológico sino que lo rearticula como otro fenómeno existencial, la angustia de existir. Esta angustia se deriva de la experiencia de la muerte ajena, la cual produce, según Freud, un sentimiento ambivalente de dolor y satisfacción. Por un lado, la experiencia no vivencial de este fenómeno conlleva la muerte parcial del propio superviviente, pues éste experimenta la posibilidad de una finitud, no solamente futura, sino también cierta. Por otro lado, la muerte del prójimo implica también una satisfacción inconsciente, pues aquello que es extraño en el otro desaparece, lo cual no queda exento de un sentimiento de culpabilidad ontológica -o de un sentimiento de angustia no atribuible a causa específica alguna-, el cual que forma parte del proceso de supervivencia. En cuanto a la culpabilidad óntica, su negación por parte del autor no implica la negación de la culpabilidad como fenómeno existencial, por lo que no es posible para el superviviente vencer la nulidad que implica este fenómeno ontológico.

Con objeto de superar el carácter ontológico de su consciencia, Semprún recurre también a la articulación inauténtica de la misma a través de ciertos paradigmas sobre los que se estructura la existencia óntica colectiva. El primero de estos elementos es la percepción del tiempo, fenómeno que adquiere un nuevo significado ante la certeza de la muerte. El tiempo lineal inauténtico es de carácter infinito, permitiendo al individuo eludir la consciencia de su propia finitud a través de su inmersión en la experiencia ordinaria y colectiva. De hecho, Heidegger toma de Nietzche la idea de que la razón no se puede formular desde una consciencia infinita de la existencia, por lo que el carácter ontológico del Dasein es radical en su consciencia de la finitud del tiempo, siendo éste un pilar sobre el que se fundamenta su existencia auténtica como ser-para-la-muerte: «What is authentic must be finite. Authentic existence means to be aware of the possibility of not-being, to be aware of one's finitude. To be is to be in time» (Gelven 225).

La articulación de la conciencia auténtica del Dasein en base al tiempo inauténtico requiere la percepción de este fenómeno en base a su infinitud e indeterminación, de forma que el Dasein pueda alejarse de su propia muerte a través de la superación de la consciencia de su existencia como algo finito y posible: «Resultaba estimulante imaginar que el hecho de envejecer no iba a acercarme a la muerte, sino por el contrario a alcjarme de ella» (27). Esta percepción inauténtica del tiempo justifica el énfasis de Semprún en las referencias temporales tras salir del campo de concentración, aspecto que muestra su propósito de reinsertarse en una existencia óntica y ordinaria. Por un lado, estas referencias permiten al testigo enfatizar su credibilidad de cara al lector de su relato, mientras que, por el otro, hacen posible para el superviviente retomar el tiempo como paradigma infinito en el que se encuentra inmerso el ser inauténtico-en-el-mundo:

Establecer la fecha inicial de este periodo resulta fácil. Figura en los libros de historia: 11 de abril de 1945, día de la liberación de Buchenwald. Es posible calcular la de mi llegada a París, pero les ahorraré las referencias empleadas. Es la antevíspera del 1 de mayo: el 29 de abril, por lo tanto. Por la tarde, para ser del todo exactos (40).

El énfasis en la temporalidad se contrarresta con el olvido selectivo del autor, el cual se extiende desde que abandona Buchenwald hasta su Ilegada a París. El testigo no abandona el campo hasta el día catorce de abril, tres días después de su liberación, llegando a la capital francesa el día veintinueve del mismo mes. Las dos semanas que transcurren entre ambas fechas están marcadas por el olvido y la confusión, no siendo posible para el superviviente relatar qué ocurrió durante cste tiempo. Este olvido marca una barrera psicológica entre la consciencia de la existencia auténtica y $\mathrm{el}$ inicio de la existencia inauténtica a la que aspira fuera de Buchenwald. De esta forma, el testigo trata de adquirir una consciencia inauténtica de su existencia como ser-en-elmundo, distinguiéndola claramente de su experiencia en el campo de concentración:

Si prácticamente he olvidado las dos largas semanas de existencia que precedieron a mi regreso a la vida, a lo que llaman vida, no se debe a un fallo de la memoria. El hecho, sin embargo está ahí: no conservo de ese periodo más que recuerdos dispersos, sueltos, con los que llevar apenas unas horas de aquellas dos largas 


\section{DANIEL ARROYO RODRÍGUEZ}

semanas. Unos recuerdos que brillan con luz intensa, por supuesto, pero que están cercados por la tonalidad gris del no ser (40).

Otro paradigma colectivo que permite al Dasein traspasar su conciencia al ámbito colectivo de lo inauténtico, de lo ordinario, lo constituye el concepto de la habladuría (Gerede), a través del cual se articula la conciencia de la existencia propia en base al lenguaje ${ }^{20}$. En relación a este paradigma, la habladuría hace posible la comunicación del Dasein con otros sujetos ónticos, al ser el medio a través del cual tiene lugar la comprensión y la interpretación colectiva en el día a día (Heidegger 211). A través de este paradigma, el Dasein se sitúa como scr-con-el-otro, estableciendo una relación con otros individuos como posibilidad de existencia y tratando de superar de este modo su carácter cspectral. Si bien en la experiencia del campo la transformación en humo y cenizas impide la existencia del Dasein en su relación con otros, la habladuría reinstaura esta forma de existir en el mundo. Este fenómeno inauténtico permite al sujeto suspender el cuestionamiento de su finitud, superando el carácter no relacional de la consciencia de la muerte y sirviéndole de medio a través del cual abandonarse a la existencia inauténtica:

To be unrooted in this manner is a possibility of being only for an entity whose disclosedness, in such an ontologically constitutive state, is its 'there' its 'in the world', far from amounting to a 'not being' of dasein. This uprooting is rather dasein's most everyday and most stubborn reality (Heidegger 214).

Este abandono a la realidad colectiva implica una perversión del carácter revelador del lenguaje (Erschliessen), pues la comprensión de la habladuría no va más allá de lo aparente, lo que imposibilita cualquier indagación sobre la realidad ontológica: «[...] an understanding of what is talked about is supposedly reached in idle talk. Because of this, idle talk discourages any new inquiry and any disputation and in a peculiar way suppresses them and holds them back» (Heidegger 213). El testimonio de Semprún puede entenderse como una manifestación de este fenómeno, al permitir la comunicación del testigo como sujeto óntico pero no de su consciencia ontológica, pues esta última constituye una laguna inaccesible al lenguaje ordinario, como reflexiona Semprún en base a los testimonios de Primo Levi y de Celan. De hecho, la habladuría distingue el testimonio de Semprún del de estos otros supervivientes: mientras estos últimos tratan de revelar la consciencia auténtica de la existencia, Semprún diluye el carácter ontológico de su consciencia en la expresión no indagatoria de la habladuría. Este aspecto justifica la complejidad del testimonio poético de Celan y la aparente simplicidad con la que Semprún articula su relato, pues este último se dirige a un lector óntico sumido en una existencia ordinaria. Por ello, Semprún opta por el relato autobiográfico sobre la expresión artística o poética, aun cuando reconoce que la única posibilidad de transmitir parcialmente la sustancia de la experiencia ontológica radica en la expresión lírica ${ }^{21}$ :

Sólo alcanzarán esta sustancia, esta densidad transparente, aquellos que sepan convertir su testimonio en un objeto artístico, en un espacio de creación o de recreación. Unicamente el artificio de un relato dominado conseguirá transmitir parcialmente la verdad del testimonio (25).

No obstante, la intención del testigo no es la de revelar la esencia de la experiencia auténtica, posibilidad que el escritor asocia a los suicidios de Celan y de Primo Levi, sino la de liberarse de esta conciencia. Por ello, el autor utiliza el relato autobiográfico en lugar de la poesía como forma a través de la cual revelar su experiencia tanto del campo de concentración como del periodo que sigue a esta etapa.

20.- «Terminologically, it signifies a positive phenomenon which constitutes the kind of Being of everyday Dasein's understanding and interpreting. For the most part, discourse is expressed by being spoken out, and has always been so expressed; it is language» (Heidegger 211).

21.- En este sentido, podemos entender la célebre negación de Walter Benjamín de la propuesta de Theodor Adorno de que no es posible la poesía después de Auschwitz; por el contrario, según Benjamin, sólo a través de la poesía y del arte es posible la comunicación de la consciencia ontológica, perspectiva que comparten Semprún, Celan y Primo Levi. 
El uso de la habladuría constituye también una evasión de la consciencia de la finitud dentro del campo de concentración. Ante la omnipresencia de la muerte, los prisioneros desarrollan un argot cuyo objeto es el de trivializar la certeza de este fenómeno y percibirlo como una realidad óntica diaria. De esta forma, este paradigma permite al Dascin alejarse de la consciencia de su temporalidad, a través, por ejemplo, de la broma y de la cotideanización de la muerte: «'Irse por la chimenea, deshacerse en humo' eran giros habituales en la jerigonza de Buchenwald. En la jerga de todos los campos, no son testimonios lo que falta. Se empleaban de todas las maneras, en todos los tonos, incluído el del sarcasmo» (24).

La habladuría controla también la forma de percibir el mundo, relacionándose de csta forma con lo que Heidegger denomina como curiosidad (Neugier). Este parámetro colectivo implica un modo ordinario de experimentar la realidad que se centra en la mera percepción, principalmente visual, y no en la comprensión ontológica de la realidad observada ${ }^{22}$. El objetivo de la curiosidad no es comprender ni asimilar ninguna verdad ontológica sino permitir al Dasein abandonarse a la realidad inauténtica. Esta percepción del mundo es de carácter volátil (Aufenthaltslosigkeit), derivando en el continuo desarraigo de la consciencia ontológica del Dasein. De esta forma, y en conjunción con la habladuría, este fenómeno permite, según Heidegger, la inmersión en la existencia inauténtica que persigue el testigo: «Curiosity, for which nothing is closed off, and idle talk, for which there is nothing that is not understood, provide themselves, that is, the Dasein which is in this manner with the guarantec of a 'life' which supposedly, is genuinely 'lively'» (Heidegger 217).

A pesar de la voluntad del testigo de superar su consciencia de la muerte, Semprún no logra adoptar una percepción inauténtica de su experiencia a través de la curiosidad. Este aspecto sc revela, por ejemplo, en la visita que las muchachas de Mission France realizan a Buchenwald días después de la liberación del campo. Las turistas improvisadas al ver la chimenea del crematorio piensan que se trata de la cocina, aspecto que refleja un contraste radical entre la percepción auténtica del guía como ser-para-la-muerte y la perspectiva inauténtica de las jóvenes como ser-enel-mundo: « ¿Y eso, es la cocina? -preguntó. Deseé estar muerto durante una fracción de segundo» (13). Ante la perspectiva inauténtica de las mujeres, el testigo las confronta con la experiencia de la muerte, haciéndoles ver los hornos, los cadáveres medio calcinados en el interior, los ganchos, los látigos, etc. La curiosidad inauténtica permite a las observadoras huir de este escenario y continuar con su existencia, dejando atrás todo aquello que habían observado: «Me giré, sc habían marchado. Habían huído del espectáculo. Las comprendía» (138).

En contraposición a la curiosidad de las visitantes, el testigo no puede cubrir el carácter ontológico de su consciencia bajo el velo de la consciencia inauténtica. De hecho, el superviviente apenas puede articular verbalmente lo que observa; por el contrario, se limita a nombrar las cosas mecánicamente, haciendo del silencio y de la falta de toda explicación el único testimonio posible: «Casi no les hablaba. Les nombraba sencillamente las cosas sin comentarios. Era necesario que vieran, que trataran de imaginar» (137). Más aún, el carácter auténtico de la experiencia del testigo, en contraste con la percepción inauténtica de las visitantes, lleva al sujeto a cuestionar su propia supervivencia: «Pensé que hacía falta haber vivido su muerte, como lo habíamos hecho nosotros, que habíamos sobrevivido a su muerte. Pero que no sabíamos aún si habíamos sobrevivido a la nuestra» (138).

La imposibilidad del testigo de readaptarse a la realidad óntica se muestra no sólo en el momento de su liberación, sino también varias décadas después. De hecho el testimonio de Semprún culmina con la expresión de esta imposibilidad de existir de forma inauténtica en el mundo, retornando a la visión ontológica del humo del crematorio cincuenta años después. De

22.- En relación a la curiosidad, Heidegger concibe el modo ordinario de percibir el mundo siguiendo la idea aristotélica de que el ser es aquello que se muestra en la contemplación, en la cual radical la verdad genuina. 


\section{DANIEL ARROYO RODRÍGUEZ}

esta forma, el autor muestra el fracaso de su intento de superar la consciencia de su finitud como ser-para-la-muerte y, por consiguiente, la imposibilidad de una supervivencia integral que vaya más allá de la existencia meramente física y corporal: «Alcé la Mirada. En la cresta del Ettersberg, unas llamas anaranjadas sobresalían de lo alto de la maciza chimena del crematorio» (330).

Para concluir, el testimonio de Semprún muestra la imposibilidad del testigo de abandonar el carácter ontológico de su consciencia y de sumergirse en la existencia inauténtica como seren-cl-mundo. A pesar de la intención del autor de superar la culpabilidad, Semprún, a través de su relato, sólo puede negar este fenómeno como experiencia óntica, no ontológica, rearticulando este elemento existencial en función de otro fenómeno, la angustia de existir. De igual forma, aún cuando el escritor trata de articular su consciencia en base a la temporalidad infinita, la habladuría y la curiosidad, estos parámetros colectivos solamente le permiten expresar parcialmente su experiencia de la muerte, no la superación de la consciencia de este fenómeno. Por consiguiente, el testimonio de Semprún, si bien da fe de si supervivencia física, muestra también su imposibilidad de superar la consciencia ontológica, no pudiendo retornar a la existencia ordinaria previa a la experiencia de Buchenwald.

\section{OBRAS CITADAS}

Agamben, Giorgio. Remnants of Auschwitz: The Witness and the Archive. New York: Zone Books, 1999.

Arendt, Hannah. The Origins of Totalitarianism. New York: Harcourt Brace Jovanovich, 1973.

Cruz, Manuel. Filosofía contemporánea. Madrid: Taurus, 2002.

Denker, Alfred. Historial Dictionary of Heidegger's Philosophy. Lanham: Scarewcrow Press, INC., 2000.

Derrida, Jacques. "A Self-Unscaling Poetic Text: Poetics and Politics of Witnessing". Revenge of the Aesthetic: The Place of Literature in Theory Today. Berkeley: University of California UP, 2000 .

- Espectros de Marx. El estado de la deuda, el trabajo del duelo y la nueva Internacional. 4." ed. Madrid: Editorial Trotta, 2003.

— The Gift of Death. Chicago: The University of Chicago Press, 1995.

Felman, Soshana and Laub Dori. "Education and Crisis, Or the Vicisitudes of Teaching". Testimony. New York: Routledge, 1992.

Freud, Sigmund. "Consideraciones de actualidad sobre la gucra y la muerte". Sigmund FreudObras completas. Coursepack, Español, 855, otoño 2004, 2101-2117.

- "El porqué de la guerra". Sigmund Freud- Obras completas. Coursepack, Español, 855, otoño 2004, 3207-3215.

_ "Mourning and Melancholy". The Standard Edition of the Complete Psychological Works. 23 vols. Ed. and Trans, James Strachey. London: Hogarth Press, 1953-1974.

Gelven, Michael. A Commentary on Heidegger's Being and Time. New York: Harper \& Row, Publishers, 1970.

Gusmán, Luis. "La inscripción en la piedra”. Epitafios: el derecho a la muerte escrita. Buenos Aires: Grupo Editorial Norma, 2005.

Halbwachs, Maurice. On Collective Memory. Chicago: The University of Chicago Press, 1992.

Heidegger, Martin. Being and Time. New York: Harper \& Row Publishers, 1962. 


\section{EL TESTIMONIO COMO IMPOSIBILIDAD DE SOBREVIVIR...}

Homer, Frederic, D. Primo Levi and the Politics of Survival. Columbia: University of Missouri Press, 2001.

Prauss, Gerold. Knowing and Doing in Heidegger's Being and Time. New York: Humanity Books, 1999.

Semprún, Jorgc. La escritura o la vida. Barcelona: Fábula Tusquets Editores, 1995.

Tidd, Ursula. "The Infinity of Testimony and Dying in Jorge Semprún's Holocaust Autothanathographies". Oxford Journals. Forum for Modern Languages Studies. Vol. 41, n. 4. 407-417. 